\title{
ACESSIBILIDADE URBANA NA ZONA CENTRO HISTÓRICA (ZCH) DE CAMPOS DOS GOYTACAZES, RJ
}

\section{Ronaldo de Sousa Araújo ${ }^{*}$, Ana Clara Bastos Ferreira1, Myriã Soares Souhait Teixeira' \& Rebeca Caldas Martins ${ }^{1}$}

\section{RESUMO}

ARAÚJO, R.S.; FERREIRA, A.C.B.; TEIXEIRA, M.S.S.; MARTINS, R.C. Acessibilidade Urbana na Zona Centro Histórica $(\mathrm{ZCH})$ de Campos dos Goytacazes - RJ. Perspectivas Online: Humanas e Sociais Aplicadas, v. 9, n.25, p.1-13,2019.

Neste artigo apresenta-se um estudo sobre aspectos físicos estruturais de acessibilidade no centro histórico da cidade de Campos dos Goytacazes - RJ, área denominada Zona Centro Histórica $(\mathrm{ZCH})$. O objetivo deste trabalho foi realizar um diagnóstico das condições físicas de elementos de acessibilidade previstos na NBR 9050. Em relação à metodologia utilizada foram feitas revisão bibliográfica, pesquisa documental e da legislação, levantamento in loco, análise de dados. Quanto aos resultados, foram mapeados e analisados os elementos de acessibilidade: rampas, pisos táteis, pisos elevados, calçadões e faixas de pedestres. Verificou-se que a maioria dos locais para trânsito de pedestre não apresenta rampas e piso tátil. Pode-se concluir que a Zona Centro Histórica não apresenta condições satisfatória de acessibilidade na maior parte de sua área.

Palavras-chave: Acessibilidade; Centro Histórico; NBR 9050; Urbanismo. 


\begin{abstract}
This article presents a study on physical aspects of accessibility in the historical center of the city of Campos dos Goytacazes - RJ, an area called Zona Centro Histórica $(\mathrm{ZCH})$. The objective of this work was to perform a diagnosis of the physical conditions of accessibility elements foreseen in the NBR 9050. In relation to the methodology used were made bibliographic review, documentary

data analysis. As for the results, accessibility elements were mapped and analyzed: ramps, tactile floors, raised floors, pedestrian walkways and tracks. It was found that most places for pedestrian traffic do not present ramps and tactile floors. It can be concluded that the Historical Center Zone does not present satisfactory accessibility conditions in most of its area.
\end{abstract} and legislation research, in situ survey,

Keywords: Accessibility; Historic Center; NBR 9050; Urbanism.

\footnotetext{
${ }^{1}$ Institutos Superiores de Ensino do CENSA - ISECENSA. Laboratório de Estudos Urbanos e Ambientais - LEUA. Curso de Arquitetura e Urbanismo. Rua Salvador Correa, 139, Centro, Campos dos Goytacazes, RJ, CEP: 28035-310, Brasil. (*) e-mail: r.saraujo100@gmail.com Data de recebimento: 05/04/2019. Aceito para publicação: 30/08/2019.
} 


\section{INTRODUÇÃO}

As áreas urbanas centrais passam, ao longo do tempo, por um processo de envelhecimento que as tornam incompatíveis com as necessidades da sociedade contemporânea. Estas áreas normalmente são locais antigos das cidades e abrigam um acervo importante do patrimônio. Como são áreas vulneráveis, necessitam de medidas de conservação. Um marco para a preservação do patrimônio foi a "Convenção para a Proteção do Patrimônio Mundial, Cultural e Natural" instituída na Conferência Geral da Organização das Nações Unidas para a Educação, Ciência e Cultura (UNESCO, 1972).

A área de estudo desta pesquisa é a denominada Zona Centro Histórica - ZCH de Campos dos Goytacazes, RJ (Mapa 01: Zoneamento Urbano, Anexo III, Figura 1) ou Zona de Comércio do Centro Histórico (Lei n.7.974/2008, Art. 68). Uma região que, além do interesse histórico, abriga o principal centro comercial e de serviços da cidade. São muitos os problemas encontrados nesta região, em que pode-se destacar o desaparecimento de edificações de interesse histórico (ARAÚJO, 2018), a carência de habitações, a falta de arborização e/ou a deficiência em acessibilidade. Este último aspecto é o objeto desta pesquisa.

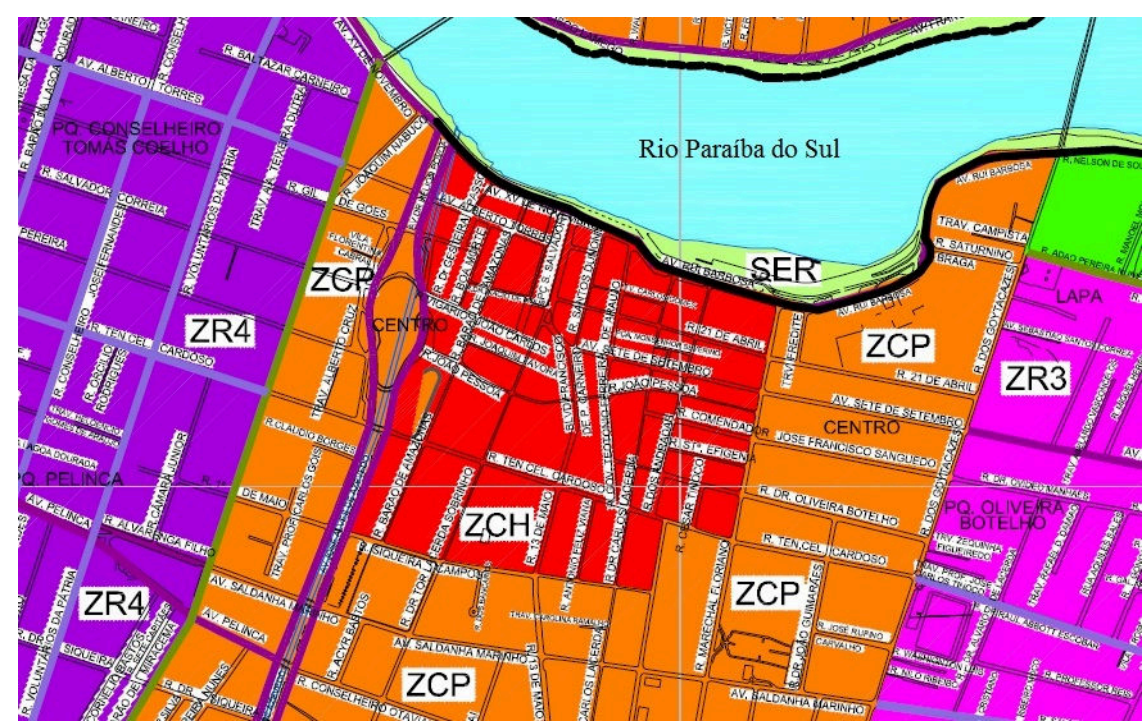

Figura 1. Mapa com a Zona Centro Histórica $(\mathrm{ZCH})$ de Campos dos Goytacazes. Fonte: Anexo III da Lei n. 7.974 / 2008, de Uso e Ocupação do Solo do Município de Campos dos Goytacazes, RJ.

Em 2010 o IBGE apontou que 45.606.048 de brasileiros possuíam algum tipo de deficiência (visual, auditiva, motora e mental ou intelectual), isso correspondia a $23,9 \%$ da população do país. Destas, 38.473.702 viviam em áreas urbanas e 7.132.347 estavam nas áreas rurais. A ocorrência maior foi a deficiência visual com 18,6\% da população, a deficiência motora ficou em segundo lugar com $7 \%$, a deficiência auditiva correspondeu a $5,1 \%$ e a deficiência mental ou intelectual com 1,4\%. (OLIVEIRA, 2012).

No Brasil, a principal referência de elementos construtivos necessários para a acessibilidade é a norma técnica NBR 9050 (ABNT, 2015). Esta norma estabelece critérios e parâmetros técnicos para se conseguir espaços acessíveis. Elementos como rampas, faixas de pedestres e pisos táteis são especificados pela norma. Segundo a norma técnica (ABNT, 2015, p. 2), acessibilidade é:

Persp. Online: hum \& sociais aplicada., Campos dos Goytacazes, 25 (9) 1-13 - 2019 seer.perspectivasonline.com.br 
Possibilidade e condição de alcance, percepção e entendimento para utilização, com segurança e autonomia, de espaços, mobiliários, equipamentos urbanos, edificações, transportes, informação e comunicação, inclusive seus sistemas e tecnologias, bem como outros serviços e instalações abertos ao público, de uso público ou privado de uso coletivo, tanto na zona urbana como na rural, por pessoa com deficiência ou mobilidade reduzida.

Além da norma técnica, o Brasil dispõe de outras referências, como a Lei $n^{\circ} 10.098$ (BRASIL, 2000) que estabelece normas e critérios para a promoção da acessibilidade para as pessoas portadoras de deficiência ou com mobilidade reduzida. Esta lei determina a supressão de barreiras e de obstáculos nas vias e espaços públicos, assim como no mobiliário, na construção e reforma de edifícios e também nos meios de transporte e comunicação.

Em relação as definições, de acordo com a Lei n 12.587 (BRASIL, 2012), que institui as diretrizes da Política Nacional de Mobilidade Urbana:

Mobilidade urbana: condição em que se realizam os deslocamentos de pessoas e cargas no espaço urbano;

Acessibilidade: facilidade disponibilizada às pessoas que possibilite a todos autonomia nos deslocamentos desejados, respeitando-se a legislação em vigor.

Em 2015 foi instituída a Lei $\mathrm{n}^{\mathrm{o}} 13.146$ (BRASIL, 2015), denominada Estatuto da Pessoa com Deficiência. Esta lei estabelece, de forma ampla, princípios para assegurar e promover os direitos fundamentais para a pessoa com deficiência, visando à sua inclusão social e cidadania. A acessibilidade é citada (art. 53) como direito que garante à pessoa com deficiência ou com mobilidade reduzida viver de forma independente e que possa exercer seus direitos de cidadania e de participação social. Com esta lei, segundo Gabrilli (2016, p. 10), ficou "clara e definida a responsabilidade das Prefeituras em zelar pela gestão da conservação e construção das calçadas".

Uma das grandes demandas das cidades atualmente é a humanização de seus espaços. A preocupação com a qualidade de vida está sendo, cada vez mais, primordial no planejamento urbano. Entre os aspectos importantes para a humanização e a qualidade dos espaços, a acessibilidade é um fator essencial. Como observa Soutinho (2012), o urbanismo contemporâneo tornou a condição humana fundamental para o projeto dos espaços públicos.

Jacobs (2011) destaca que as calçadas, que são as partes das ruas destinadas aos pedestres, servem para várias finalidades e não somente a de abrigar pedestres. Cada um desses usos é tão importante quanto a circulação para que a cidade tenha um funcionamento adequado.

Segundo Gehl (2015) as cidades devem ser boas para caminhar. De acordo com o autor, deve haver uma política para convidar o tráfego de pedestres na cidade. Neste sentido, é preponderante que as calçadas tenham qualidade.

Calçadas qualificadas estimulam as pessoas a se deslocarem a pé, o modo de transporte mais natural que existe. Uma maior ocupação da cidade por pedestres amplia as possibilidades de convivência, reforça a identidade dos lugares, aumenta a qualidade de vida e a saúde da população, além de fomentar o comércio e garantir maior segurança nos espaços públicos (IPUF, 2018, p. 7).

Um estudo do IPHAN (2014), sobre mobilidade e acessibilidade em centro histórico, destaca que nessas áreas a maioria das barreiras pode ser reduzida, mediante a atenção do

Persp. Online: hum \& sociais aplicada., Campos dos Goytacazes, 25 (9) 1-13 - 2019 
poder público e de particulares, assim irá garantir o direito de locomoção das pessoas, como determina a Constituição Federal (BRASIL, 1988).

De acordo com documento do Ministério das Cidades (2015), os Planos de Mobilidade Urbana não devem tratar apenas de veículos, mas também da circulação de pessoas e bens, priorizando o pedestre e o transporte coletivo e não somente o automóvel. $\mathrm{O}$ planejamento viário deve estar relacionado, entre outros aspectos, aos princípios de acessibilidade universal.

Em um processo de revisão e atualização de um plano diretor, modificação legal no planejamento urbanístico (ARAÚJO, 2009), aspectos como acessibilidade podem ser tratados de forma a corrigir e atualizar eventuais pendências e defasagem para se conseguir um espaço urbano de qualidade.

Vale dizer que Desenho Universal é o parâmetro que tem ganhado atenção crescente, visto que busca alcançar a maior gama de pessoas, sejam de qualquer tamanho, postura ou condições de mobilidade (MONTENEGRO; SANTIAGO; SOUSA, 2009). Com este conceito, considera-se não só o projeto, mas principalmente a diversidade humana, respeitando as diferenças das pessoas e garantindo a acessibilidade aos componentes do ambiente (SEPED, 2005).

Assim, diante da abrangência do tema optou-se em delimitar a pesquisa de acessibilidade no espaço público, especificamente calçadas, calçadões e praças no centro histórico da cidade de Campos dos Goytacazes.

O Plano Diretor de Campos dos Goytacazes, Lei $n^{0}$ 7.972, observa (Art.75) que para garantir a acessibilidade de todos, "a requalificação dos espaços públicos e adaptação dos espaços privados e dos serviços de transporte" é estratégia de acessibilidade universal no Município. O plano também determina (Art.76) a elaboração de estudos para a normatização das calçadas de acordo às normas universais de mobilidade e acessibilidade urbana, e vincula o Plano de Acessibilidade Universal - PLAU ao Plano Cicloviário municipal (CAMPOS DOS GOYTACAZES, 2008).

Este trabalho teve como objetivo levantar a situação em que se encontra os espaços públicos do centro histórico de Campos dos Goytacazes, em relação às condições de acessibilidade. Desta forma, foi realizado um diagnóstico dos elementos de acessibilidade no local, e que estão previstos na norma NBR 9050 de 2015. A motivação para a realização desta pesquisa está apoiada na necessidade de humanização das cidades em função das exigências contemporâneas, e que a cidade de Campos reflete esta demanda em seu espaço público. Um trabalho que faz parte do Programa Voluntários de Iniciação Científica - PROVIC dos Institutos Superiores de Ensino do Censa - ISECENSA. O Projeto de Pesquisa teve como título "Diagnóstico do Centro Histórico de Campos dos Goytacazes: Aspectos Urbanísticos e Ambientais".

\section{METODOLOGIA}

Para a realização deste trabalho foram realizadas: pesquisa bibliográfica sobre acessibilidade em centros históricos; pesquisa documental sobre a Zona Centro Histórica ZCH de Campos dos Goytacazes (leis e mapas); levantamento in loco das condições físicas dos elementos urbanísticos de acessibilidade na ZCH (mapeamento de rampas existentes, pisos elevados, calçadões, faixas de pedestres e pisos táteis); levantamento de inclinação de

Persp. Online: hum \& sociais aplicada., Campos dos Goytacazes, 25 (9) 1-13 - 2019 seer.perspectivasonline.com.br 
rampas com utilização de nível com bolha de ar e trena; registro fotográfico; tabulação e análise de dados.

\section{RESULTADOS E DISCUSSÃO}

Com o levantamento in loco foi possível caracterizar e mapear a situação dos elementos de acessibilidade na Zona Centro Histórica de Campos. No mapa de acessibilidade (Figura 2) pode-se verificar que a maior parte das calçadas não dispõe de rampas nos locais necessários para a circulação de pessoas. Algumas ruas não dispõem de nenhuma rampa em toda sua extenção. Também foi observado no mapa (Figura 2), que as rampas ocorrem mais à direita da ZCH (região a leste), são locais onde houveram remodelações urbanisticas. Também ocorrem pisos elevados na região da Praça São Salvador (Figura 3a) e calçadões em algumas vias, como a Avenida 7 de Setembro (Figura 3b). Na Avenida XV de Novembro (Beira Rio), em frente à Praça São Salvador, observa-se faixas de pedestres com rampas e sem rampas de acessibilidade (Figura 4).

Em números, o levantamento apontou um total de 26 pisos elevados, 3 calcadões, 27 rampas, 30 faixas de pedestre e 235 calçadas sem rampa. Em relação a piso elevado, percebese que falta uma melhor sinalização e trabalho educativo voltado para motoristas em relação à priorização do pedestre nesses locais. Verificou-se uma grande utilização dos pedestres nas áreas de calçadões, e que há alguns problemas de manutenção o que acarreta risco para as pessoas. Das rampas existentes verificou-se que a inclinação, em grande parte, ultrapassa o máximo permitido pela norma técnica. Encontram-se também situações em que existe rampa apenas de um lado da rua. No tocante a faixa de pedestre foi verificado que a maior parte dos locais de transposição de pedestres nas ruas, não dispõe deste elemento de sinalização urbana. No tocante a piso tátil, este elemento é encontrado apenas nos locais onde ocorreram obras de requalificação. E o que mais chama a atenção nos números é a grande quantidade de calçadas sem rampa de acessibilidade.

Persp. Online: hum \& sociais aplicada., Campos dos Goytacazes, 25 (9) 1-13 - 2019 


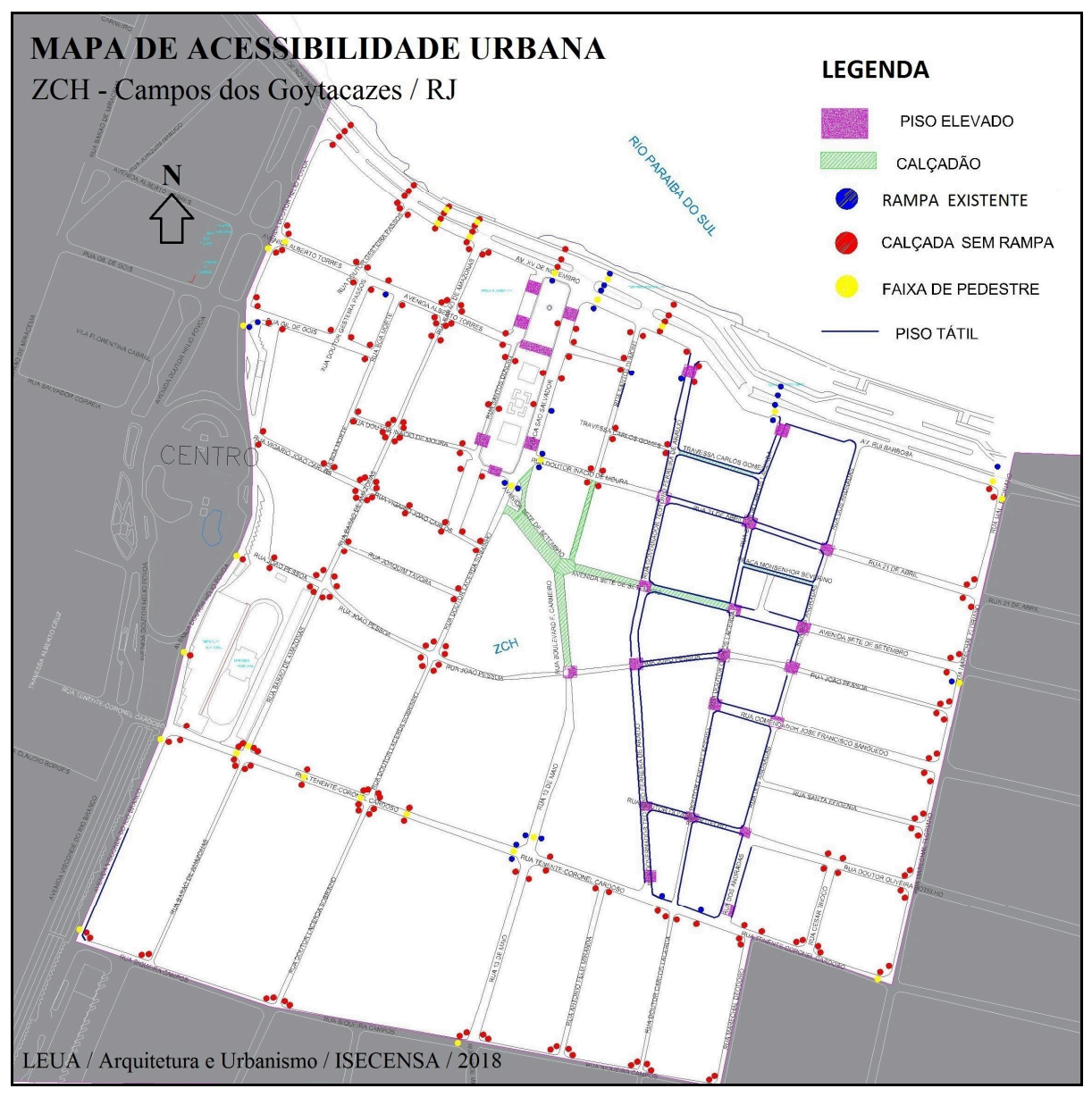

Figura 2. Mapa de acessibilidade urbana da Zona Centro Histórica de Campos dos Goytacazes, RJ. Fonte: Mapa base da Prefeitura de Campos dos Goytacazes editado com informações dos autores.
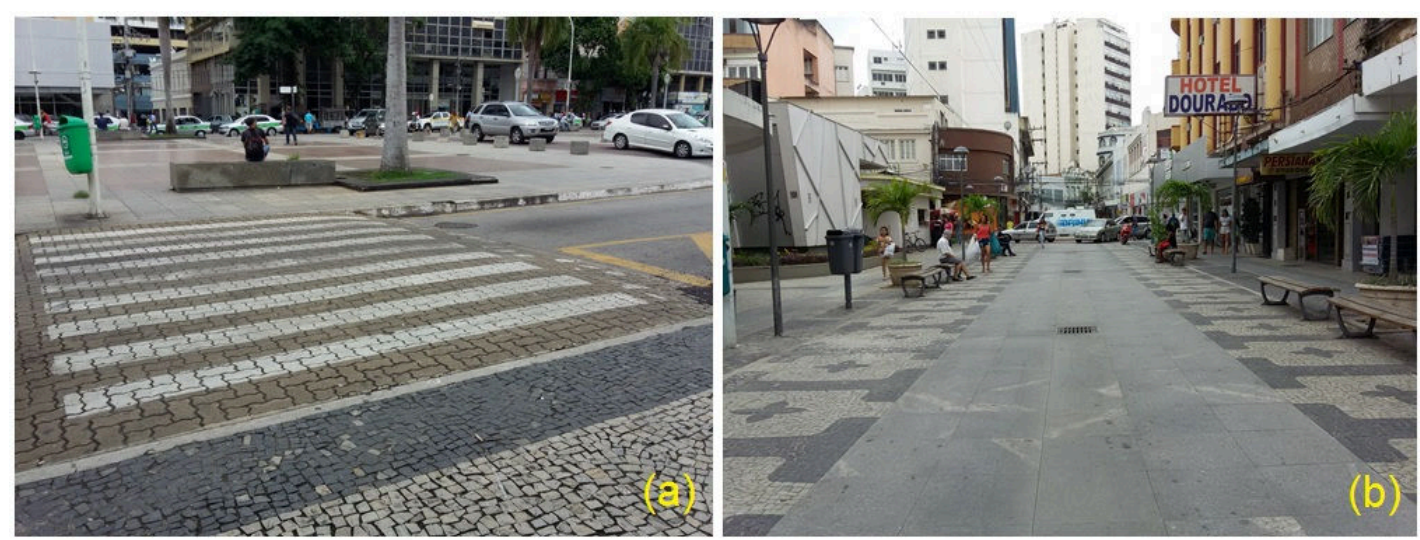

Figura 3. Piso elevado na Praça São Salvador (a), e calçadão na Avenida 7 de Setembro (b) na Zona Centro Histórica de Campos dos Goytacazes, RJ. 


\section{PERSPECTIVAS online}
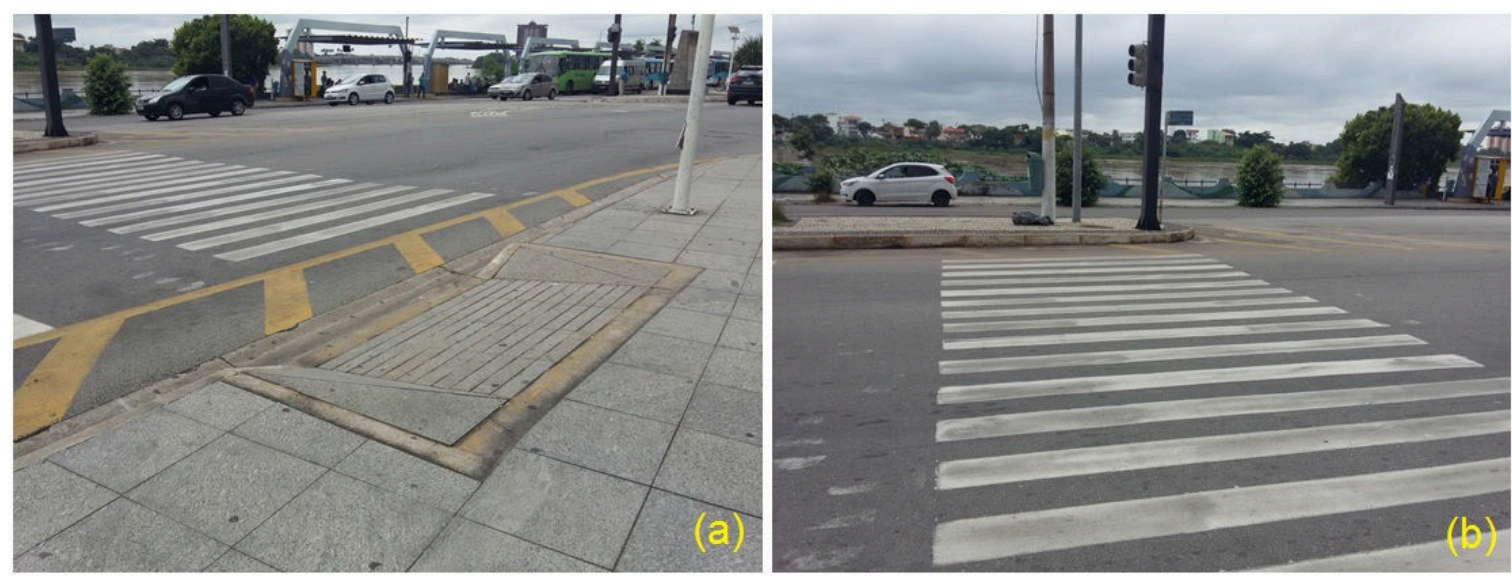

Figura 4. Rampa de acessibilidade e faixa de pedestre (a), e local sem rampa (b) na Zona Centro Histórica de Campos dos Goytacazes, RJ.

\section{Obstáculos no Espaço Público}

Além do déficit de elementos de acessibilidade no local, verifica-se também grande incidência de obstáculos no espaço público que inviabilizam a acessibilidade. Nas imagens a seguir, observa-se exemplos destes obstáculos: postes interrompendo a circulação, calçadas estreitas, construções fora do alinhamento de calçadas, degraus e desníveis acentuados etc.

Na Figura 5(c), onde se pode observar uma calçada estreita com poste interrompendo a acessibilidade, verifica-se que o muro existente conta com alinhamento fora do padrão da via/passeio. Neste caso, a ampliação da calçada pode ser viabilizada com desapropriação de parte do terreno. As desapropriações por utilidade pública estão previstas no Decreto-Lei $\mathrm{n}^{\mathbf{o}}$ 3.365 (BRASIL, 1941) e alterações da Lei nº 9.785/1999.
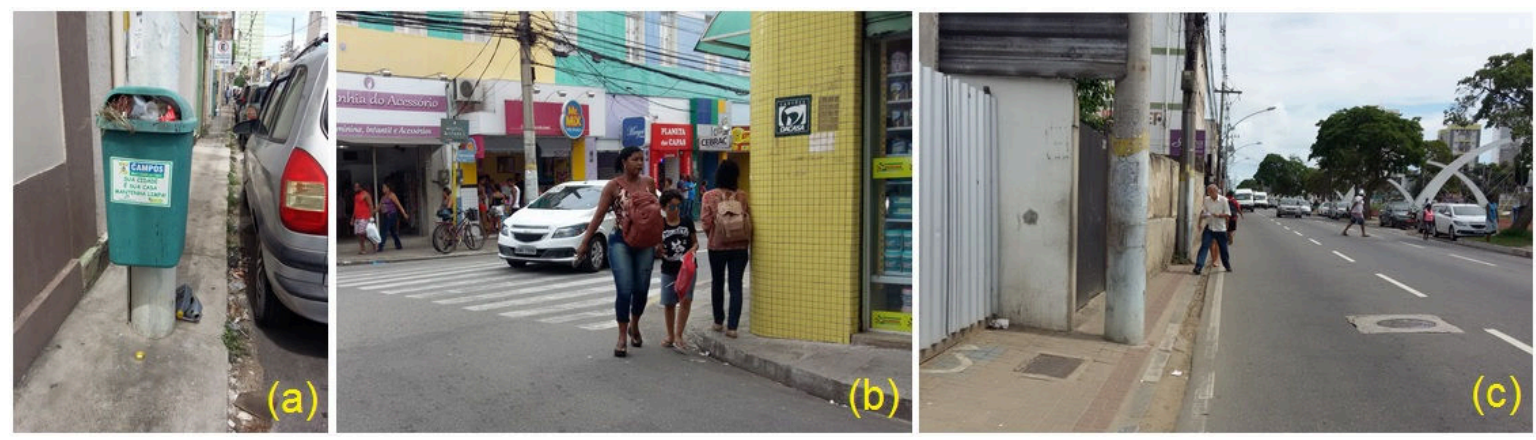

Figura 5. Calçada estreita com poste e lixeira (a), esquina com calçada estreita (b), e muro avançando sobre a calçada (c) na Zona Centro Histórica de Campos dos Goytacazes, RJ.

O mal uso dos espaços públicos ocorre em vários locais da Zona Centro Histórica, onde a região de maior incidência é nas proximidades do Mercado Municipal, que é uma edificação de interesse histórico. Frequentemente são encontrados carros estacionados nas calçadas, disposição de mercadorias e barracas de ambulantes (Figura 6b e 6c). Uma região que reflete o acúmulo de atividades que presionam o espaço público. Atividades que ao longo do tempo resultaram na construção da feira coberta e do camelódromo. Atualmente estas construções interferem na paisagem e prejudicam a qualidade histórica do Mercado e seu entorno. Carros estacionados em calçada também também ocorrem nas proximidades da ponte (Figura 6a).

Persp. Online: hum \& sociais aplicada., Campos dos Goytacazes, 25 (9) 1-13 - 2019 


\section{PERSPECTIVASonline}
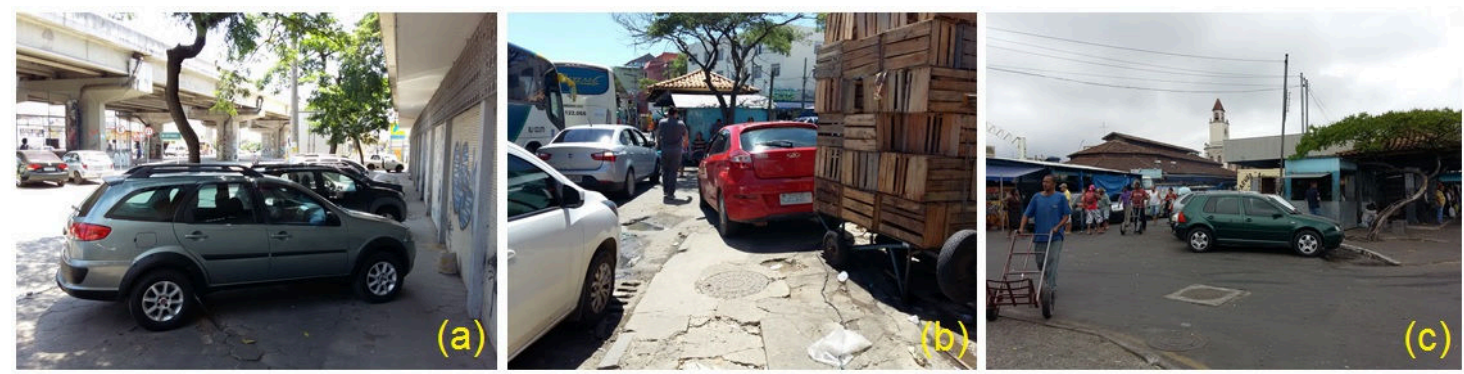

Figura 6. Mal uso dos espaços públicos na Zona Centro Histórica de Campos dos Goytacazes, RJ.
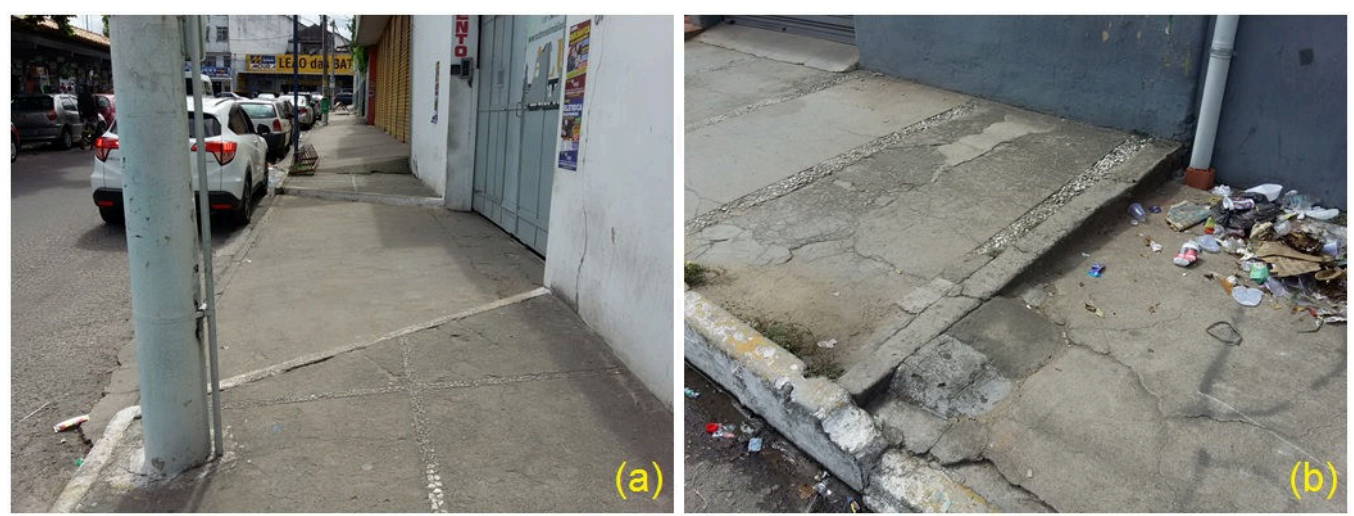

Figura 7. Degraus e desníveis acentuados na Zona Centro Histórica de Campos dos Goytacazes, RJ.

Calçadas em condições ruins dificultam a acessibilidade em algumas áreas da Zona Centro Histórica de Campos. Degraus e desníveis acentuados (Figura 7), grelhas para a drenagem de água pluvial quebradas, obras inacabadas e pedras portuguesas da pavimentação soltas, são alguns dos problemas encontrados (Figura 8).
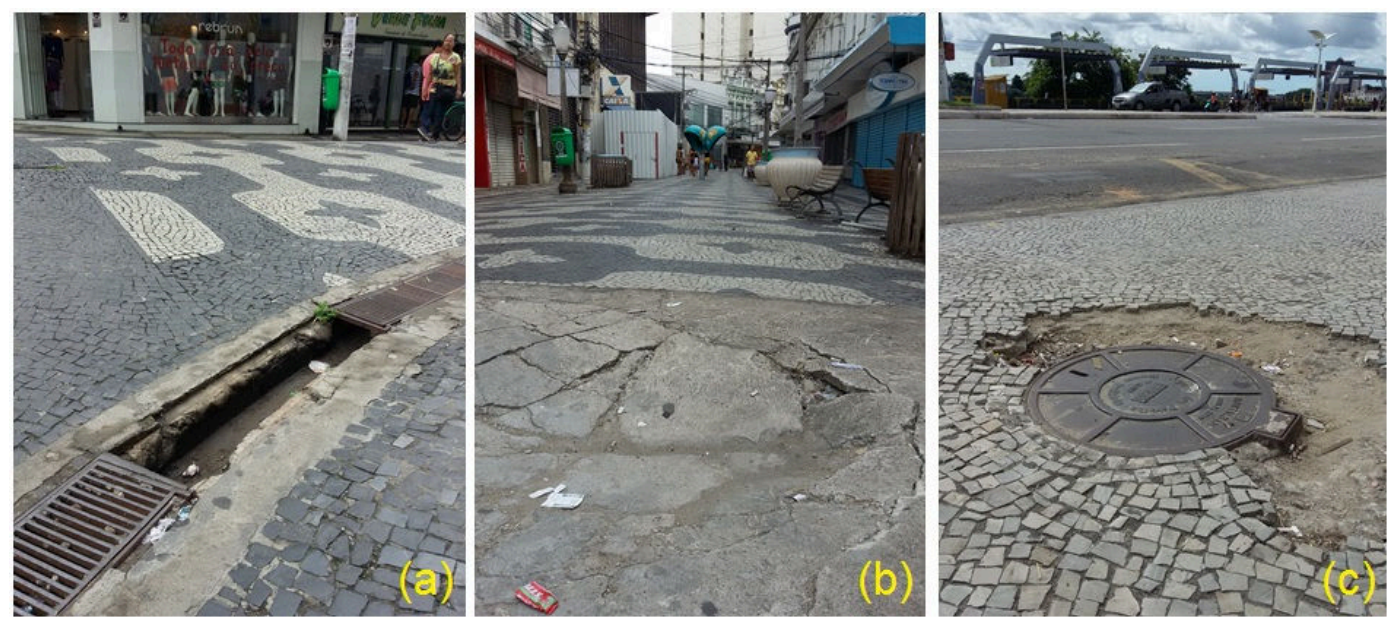

Figura 8. Más condições das calçadas na Zona Centro Histórica de Campos dos Goytacazes, RJ.

A cidade tem sido adaptada para atender as novas demandas da sociedade em cada época. Muitas dessas mudanças foram realizadas em função de incluir o automóvel. A preocupação com os deficientes é uma demanda recente.

Persp. Online: hum \& sociais aplicada., Campos dos Goytacazes, 25 (9) 1-13 - 2019 seer.perspectivasonline.com.br 
Analizando os dados coletados na Zona Centro Histórica de Campos pode-se verificar que, apesar de algumas intervenção para melhorar a acessibilidade, a maior parte da região não atende à norma da ABNT, NBR 9050.

Somada as várias situações que dificultam a acessibilidade na $\mathrm{ZCH}$ encontramos também a interrupção do passeio para acesso de veículos (Figura 9a), que segundo Gehl (2015) uma solução para este problema é a continuidade da calçada de forma que não haja interrupão, sendo necessária pequena rampa de acesso (Figura 9b).
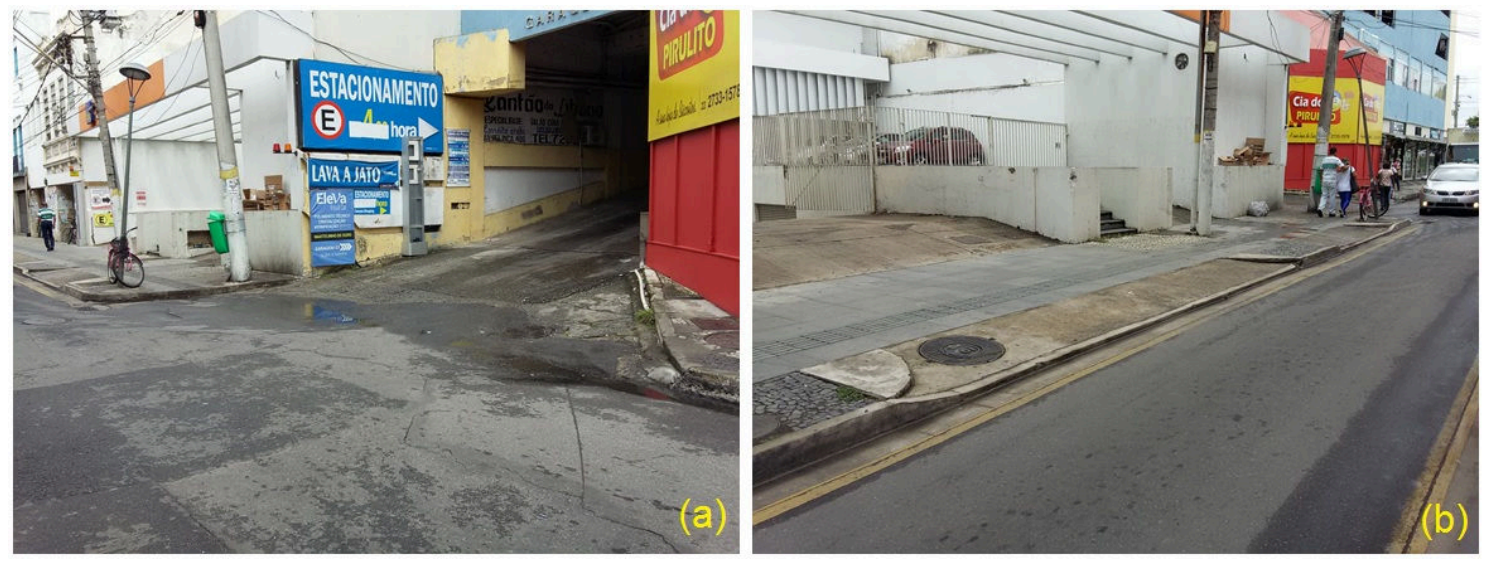

Figura 9. Interrupção de calçada (a) e continuidade de calçada (b) na Zona Centro Histórica de Campos dos Goytacazes, RJ.

A NBR 9050 indica que a inclinação máxima para rampas não deve ultrapassar 8,33 \%. Entretanto, para casos de reforma onde se esgotaram todas as possibilidades de solução, admite-se inclinação de até $12,5 \%$. Na ZCH estudada verificou-se (Figura 10), que muitas das rampas têm inclinação acima destes valores.
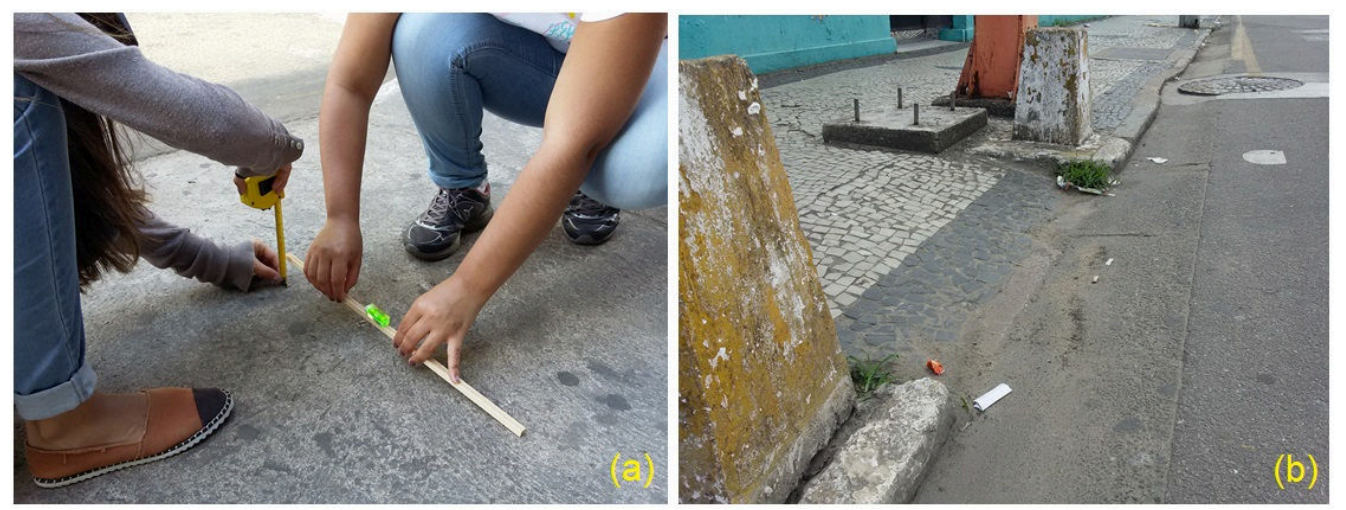

Figura 10. Medição (a) e exemplo de rampa com inclinação acima do indicado pela norma técnica (b), Zona Centro Histórica de Campos dos Goytacazes, RJ.

Além dos problema já apontados, as interrupções dos pisos táteis é encontrada em várias situações. A Figura 11(a) ilustra um problema resultante da obra de requalificação de algumas vias na $\mathrm{ZCH}$, em que o poste da rede de energia não foi retirado resultando na interrupão do piso tátil direcional. Na Figura 11(b) se observa a interrupção do piso tátil em um trecho de calçada e na Figura 11(c) a falta de manutenção da pavimentação.

Persp. Online: hum \& sociais aplicada., Campos dos Goytacazes, 25 (9) 1-13 - 2019 seer.perspectivasonline.com.br 


\section{PERSPECTIVAS online}
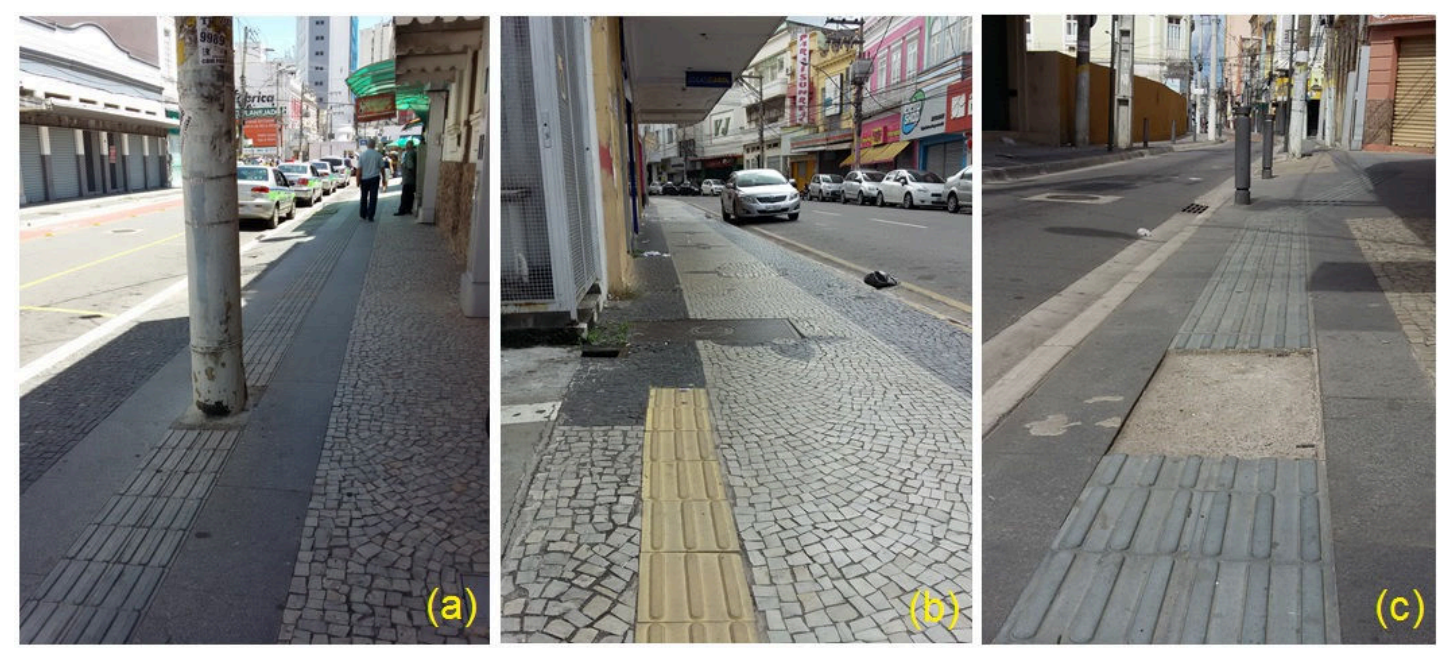

Figuras 11. Interrupção do piso tátil por existência de poste (a), falta de colocação (b), e avaria (c) em calçadas da Zona Centro Histórica de Campos dos Goytacazes, RJ.

Este estudo, que levantou aspectos quantitativos e qualitativos da Zona Centro Histórica de Campos, disponibiliza informações para o planejamento e a gestão do espaço público acessível. Verificou-se que as áreas da $\mathrm{ZCH}$ onde o poder público realizou obras de requalificação urbana (locais com piso elevado no mapa da Figura 2) apresentam melhores condições de acessibilidade que outras áreas, isto reforça o entendimento de que a ideia de passeio público implantado ou reformado pelo poder público instituída pela Lei $\mathrm{n}^{\mathrm{o}} 13.146$ de 2015 poderá melhorar a acessibilidade na cidade. A pavimentação de calçadas pelos proprietários, como disposto no Art. 75 do Código de Obras de Campos dos Goytacazes (CAMPOS DOS GOYTACAZES, 1998), não tem garantido a acessibilidade e qualidade das mesmas.

Considerando a importância cultural e o potencial turístico da Zona Centro Histórica de Campos dos Goytacazes, os estudos realizados demonstram a necessidade de maior investimento nesta região da cidade. Brito (2009) destaca que são necessárias medidas operacionais para o estabelecimento de destinos patrimoniais, como o desenvolvimento de projetos que visem a melhoria da acessibilidade física.

\section{CONCLUSÕES}

O diagnóstico realizado na Zona Centro Histórica - ZCH de Campos dos Goytacazes demonstrou que, apesar de haver na área estudada elementos de acessibilidade, ainda faltam muitas adequações no espaço urbano para se considerar o local acessível para as pessoas com deficiência ou mobilidade reduzida.

Tornar o centro histórico de Campos acessível é um desafio que deve envolver a população e a administração municipal. A acessibilidade é um dos aspectos que envolve a complexidade desta região e que a torna prioritária devido a sua condição histórica, social e econômica para a cidade.

Além das medidas para que o centro histórico seja plenamento acessível, é importante salientar que esta zona também demanda ações de preservação e valorização do patrimônio histórico, de melhoria da condições ambientais onde a arborização tem papel fundamental, e de uso adequado do espaço urbano.

Persp. Online: hum \& sociais aplicada., Campos dos Goytacazes, 25 (9) 1-13 - 2019 seer.perspectivasonline.com.br 


\section{REFERÊNCIAS}

ABNT - ASSOCIAÇÃO BRASILEIRA DE NORMAS TÉCNICAS. NBR 9050. Acessibilidade a edificações, mobiliário, espaços e equipamentos urbanos. Rio de Janeiro: ABNT, 2015.

ARAÚJO, R.S. Modificações no planejamento urbanístico: teoria e método de análise. São Paulo: Nobel, 2009.

ARAÚJO, R.S. Maquetes de transformação urbana: Praça São Salvador, Campos dos Goytacazes, RJ. Boletim de Pesquisa e Desenvolvimento do ISECENSA. Campos dos Goytacazes, v.1, n.3, 2018, pp. 15-20. Disponível em: seer.perspectivasonline.com.br. Acesso em: 18 jun. 2018.

BRASIL. Decreto-Lei $n^{0}$ 3.365, de 21 de junho de 1941. Dispõe sobre desapropriação por utilidade púbica. Rio de Janeiro: 1941.

BRASIL. Constituição da República Federativa do Brasil. Brasília: 1988.

BRASIL. Lei $\mathbf{n}^{\mathbf{0}} \mathbf{1 0 . 0 9 8}$, de 19 de dezembro de 2000. Estabelece normas gerais e critérios básicos para a promoção da acessibilidade das pessoas portadoras de deficiência ou com mobilidade reduzida. Brasília: 2000.

BRASIL. Lei $\mathbf{n}^{\mathbf{0}}$ 12.587, de 3 de janeiro de 2012. Institui as diretrizes da Política Nacional de Mobilidade Urbana. Brasília: 2012.

BRASIL. Lei $\mathbf{n}^{0}$ 13.146, de 6 de julho de 2015. Institui a Lei Brasileira de Inclusão da Pessoa com Deficiência (Estatuto da Pessoa com Deficiência). Brasília: 2015.

BRITO, M. Ciudades históricas como destinos patrimoniales. Una mirada comparada: España y Brasil. Sevilla: Junta de Andalucía, 2009.

CAMPOS DOS GOYTACAZES. Lei n 6.692 de 27 de novembro de 1998. Dispondo sobre o Código de Obras do Município de Campos dos Goytacazes. Campos dos Goytacazes: 1998.

CAMPOS DOS GOYTACAZES. Lei $\mathbf{n}^{\mathbf{0}} \mathbf{7 . 9 7 2}$, de 31 de março de 2008. Institui o plano diretor de Campos dos Goytacazes. Campos dos Goytacazes: 2008.

GABRILLI, M. Cartilha da calçada cidadã. 2016. Disponível em: maragagrilli.com.br. Acesso em: 06 ago. 2018.

GEHL, J. Cidades para pessoas. 3 ed. São Paulo: Editora Perspectiva, 2015.

IPUF - INSTITUTO DE PLANEJAMENTO URBANO DE FLORIANÓPOLIS. Calçada certa: manual de projeto e execução. Cadernos de planejamento e projetos urbanos de Florianópolis. Rede de espaços públicos. Florianópolis: IPUF/SMDU, 2018.

IPHAN - INSTITUTO DO PATRIMÔNIO HISTÓRICO E ARTÍSTICO NACIONAL. Acessibilidade e mobilidade urbana em Centro Histórico. Cadernos Técnicos, 9. Organizado por Sandra Bernardes Ribeiro. Brasília: IPHAN, 2014.

JACOBS, J. Morte e vida de grandes cidades. 1961. 3 ed. São Paulo: Martins Fontes, 2011.

Persp. Online: hum \& sociais aplicada., Campos dos Goytacazes, 25 (9) 1-13 - 2019 
MINISTÉRIO DAS CIDADES. Caderno de Referência para elaboração de Plano de Mobilidade Urbana. Brasília: SeMob, 2015.

MONTENEGRO, N.G.S.D.; SANTIAGO, Z.M.P.; SOUSA, V.C. Guia de acessibilidade: espaço público e edificações. 1. ed. Fortaleza: SEINFRA-CE, 2009.

OLIVEIRA, L.M.B. Cartilha do Censo 2010: pessoas com deficiência. Secretaria de Direitos Humanos da Presidência da República (SDH-PR) / Secretaria Nacional de Promoção dos Direitos da Pessoa com Deficiência (SNPD) / Coordenação Geral do Sistema de Informações sobre a Pessoa com Deficiência. Brasília: SDH-PR/SNPD, 2012.

SEPED - SECRETARIA ESPECIAL DA PESSOA COM DEFICIÊNCIA E MOBILIDADE REDUZIDA. Mobilidade acessível na cidade de São Paulo. Prefeitura da Cidade de São Paulo. São Paulo: CPA/SEPED, 2005.

SOUTINHO, A.M.M.S. Humanização do espaço público urbano. Dissertação de Mestrado. Universidade Católica Portuguesa. Departamento de Arquitetura, Ciências e Tecnologia. Viseu: 2012.

UNESCO - ORGANIZAÇÃO DAS NAÇÕES UNIDAS PARA A EDUCAÇÃO, A CIÊNCIA E A CULTURA. Convenção para a proteção do patrimônio mundial, cultural e natural. Paris: 1972. Disponível em: https://unesdoc.unesco.org. Acesso em: 11 maio 2018.

Persp. Online: hum \& sociais aplicada., Campos dos Goytacazes, 25 (9) 1-13 - 2019 seer.perspectivasonline.com.br 